Delft University of Technology

\title{
Comprehensive modelling and sizing of PV systems from location to load
}

Isabella, O; Ganesan Nair, Gireesh; Tozzi, A; Hernandez Castro Barreto, J; Chandra Mouli, G.R.; Lantsheer, F; van Berkel, S; Zeman, M

DOI

10.1557/opl.2015.347

Publication date

2015

Document Version

Accepted author manuscript

Published in

Proceedings of the 2015 MRS Spring Meeting and Exhibit

\section{Citation (APA)}

Isabella, O., Ganesan Nair, G., Tozzi, A., Hernandez Castro Barreto, J., Chandra Mouli, G. R., Lantsheer, F., van Berkel, S., \& Zeman, M. (2015). Comprehensive modelling and sizing of PV systems from location to load. In A. Braun, H. Fan, K. Haenen, L. Stanciu, \& JA. Theil (Eds.), Proceedings of the 2015 MRS Spring Meeting and Exhibit (pp. 17-23). (MRS Online Proceedings Library; Vol. 1771). Materials Reserach Society. https://doi.org/10.1557/opl.2015.347

Important note

To cite this publication, please use the final published version (if applicable).

Please check the document version above.

\section{Copyright}

Other than for strictly personal use, it is not permitted to download, forward or distribute the text or part of it, without the consent of the author(s) and/or copyright holder(s), unless the work is under an open content license such as Creative Commons.

\section{Takedown policy}

Please contact us and provide details if you believe this document breaches copyrights.

We will remove access to the work immediately and investigate your claim. 


\title{
Comprehensive modelling and sizing of PV systems from location to load
}

\author{
O. Isabella ${ }^{1}$, G. Ganesan Nair ${ }^{1}$, A. Tozzi ${ }^{1}$, J. H. Castro Barreto ${ }^{1}$, \\ G. R. Chandra Mouli ${ }^{1}$, F. Lantsheer ${ }^{2}$, S. van Berkel ${ }^{3}$ and M. Zeman ${ }^{1}$ \\ ${ }^{1}$ Delft University of Technology, PVMD/Dimes, Mekelweg 4, 2628 CD Delft, The Netherlands \\ ${ }^{2}$ Koninklijk Nederlands Meteorologisch Instituut (KNMI), WEER/RB\&C, PO Box 201 E De Bilt, The Netherlands \\ ${ }^{3}$ SolarNRG, Mercuriusplein 40, 2685 LP Poeldijk, The Netherlands
}

\begin{abstract}
Photovoltaic (PV) systems are progressively used for decentralized electricity generation. To obtain the maximum out of such systems optimisation of all system components is essential. In this contribution, we provide a comprehensive modelling and sizing of PV systems for any location. Three applications are here presented providing real time monitoring of PV potential, accurate prediction of yield taking into account thermodynamic temperature effects, optimization of modules orientation addressing the effects of shading and efficient sizing of inverter for a higher yield output. In conjunction, these models can predict accurately the real time performance of any PV system.
\end{abstract}

\section{INTRODUCTION}

Next to photovoltaic (PV) modules, several other devices constitute the so-called Balance of System (BoS) of a PV system. The BoS can be connected to the solar modules and to the load(s) in many different ways to form grid-connected, stand-alone or hybrid PV systems. Whatever is the topology of interest, the ratio between the power generated by PV modules and the input power is the DC-side yield, quantity always bigger than the overall yield of the PV system. This is because all BoS components, which are between the DC-side and the load, exhibit less than ideal performance because of thermal dissipation or other internal inefficiencies. However, the power delivered to the load is the benchmark value for assessing the performance of the entire PV system and for matching the load profile when sizing the PV system. Therefore a comprehensive modelling of the parts forming the PV system should be used to finally calculate the energy yield of the PV system. In this contribution we show our modelling results for (a) predicting the behaviour of PV systems based on location and real-time meteorological data, (b) sizing opportunely the DC-to-AC inverters depending on PV panels tilt and orientation and (c) applying mutual shading and environmental shading analysis on the overall yield calculation.

\section{MODELLING RESULTS AND DISCUSSION}

\section{Dutch PV portal}

The Dutch portal of photovoltaic (PV) energy (http://dutchpvportal.tudelft.nl) is a TU Delft online platform combining modelling of the electric output of PV systems with the realtime meteorological data from the Royal Netherlands Meteorological Institute (KNMI) [1]. Our website has three objectives: (i) to reveal the PV potential in the Netherlands by quantifying the real-time solar electricity production, (ii) to calculate the realistic performance of small-to-very- 
large PV systems located in The Netherlands by means of interactive design capabilities and (iii) to offer updated information on the developments in PV technologies and systems. The portal is designed and implemented for a wide audience: (inter)national governmental institutions, visitors with technical background and laymen too. The screenshot of homepage of the Dutch portal of PV energy is shown in Fig. 1

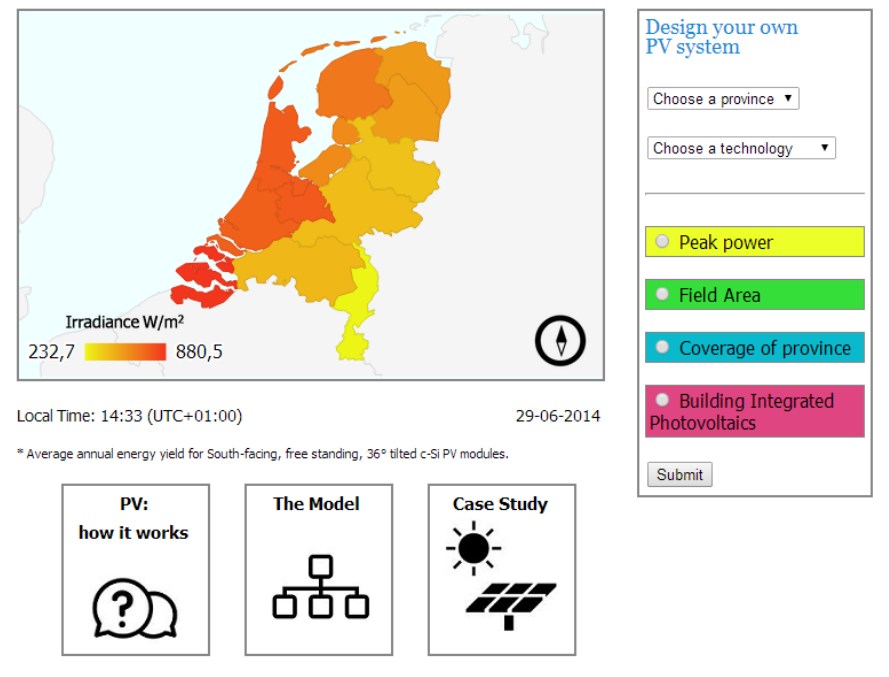

Fig. 1 Homepage screenshot of the Dutch portal of PV energy.

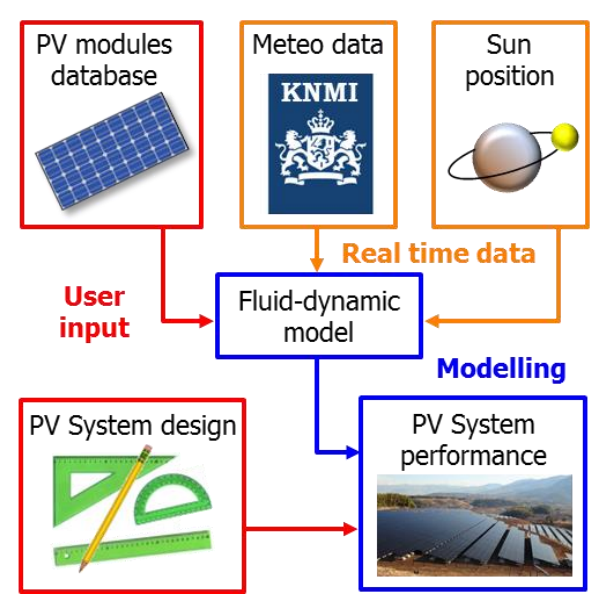

Fig. 2 Modelling flow chart of the Dutch portal of PV energy.

Fig. 2 presents the modelling flow chart used to achieve the first two goals. A set of meteorological parameters is obtained from all the weather stations located in any province of the Netherlands. These parameters are collected within 10-minute time stamp by the KNMI and subsequently processed by our Linux-Apache-MySql-Php web-application. Meteorological parameters such as ambient and ground temperature, incident (beam + diffuse) irradiance, wind speed, cloud coverage, etc. - together with an accurate sun position calculator - are our real-time input data. We use these meteorological data for calculating the irradiance per unit area on a certain territory. PV module specifications (power at the maximum power point, nominal operating cell temperature, module area, etc.) from publicly available data sheets comprise additional (static) set of input data. The visitor of the website can select one of the four PV technologies: c-Si, thin-film Si, CIGS and CdTe. These three sets of data are used as input into a fluid-dynamic model [2] that calculates the real-time module temperature of the chosen PV technology based on current meteorological conditions and taking into account heat exchange phenomena between the ambient and the PV module. The model also calculates the instantaneous DC power per unit area generated by the chosen PV technology at a selected location. The user can interactively use the portal to monitor the real-time AC power generation of a selected PV system design. As important part of the PV system design, PV array mounting and topology, mutual shading calculations and automatic choice of the inverter(s) from a vast database [3] are taken into account. The output of the PV system can be calculated for (i) province area coverage for policy makers interested in the global on-site potential of PV generation, (ii) installed peak power or (iii) installation area for experts in solar farms business, and (iv) building integrated PV for citizens willing to quantify the PV energy production capabilities of their rooftop. 
The third objective of the portal is to increase public awareness that PV energy generation is a key factor for the successful transition towards energy mix with a large share of clean energy sources. Our portal is a tool to achieve this goal by engaging the visitor in an interactive PV system design while displaying real-time calculation of power output.

\section{$\underline{\text { PV charging station }}$}

When looking at the energy yield at a specific location the output from the above analysis needs to be processed further to take into account the effects of shading from the environment. The presence of shading can affect the yield output depending on the amount of area being shaded. To accurately determine the impact of shading and the resultant actual energy output it becomes necessary to perform a shading analysis. This analysis was performed in the frame of an interdisciplinary project aimed to design a PV powered e-bike charging station that will be installed in TU Delft Campus. For our results we used the Horicatcher by Meteotest [4] to obtain the Shading Factor (SF) which was then used to de-rate the incident irradiation. Since the shading from the environment also affects the ideal orientation of the PV modules, this new incident irradiation can be used to identify the new optimal orientation of the PV modules as illustrated in Fig. 3 and Fig. 4. The figures show the variation in annual incident irradiation with azimuth and tilt for a location in TU Delft Campus, Delft, the Netherlands.

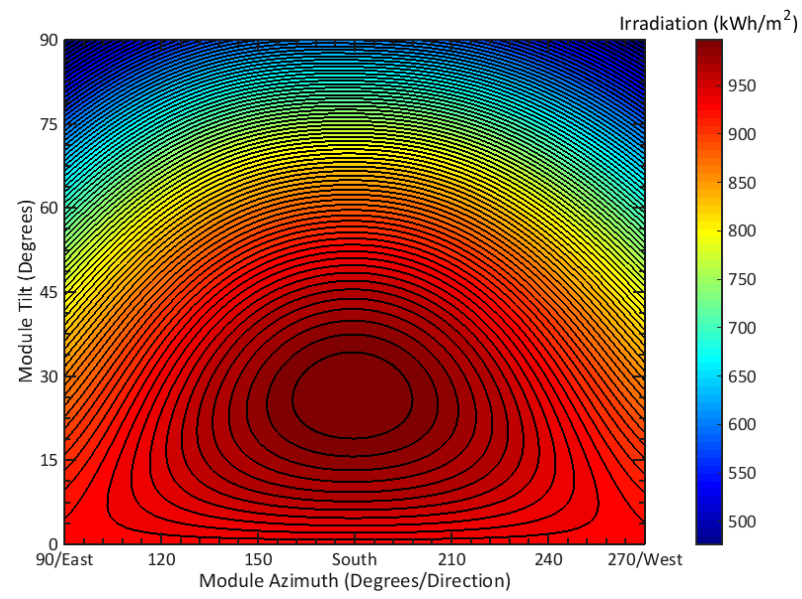

Fig. 3 PV module tilt and azimuth optimization when there is no shading.

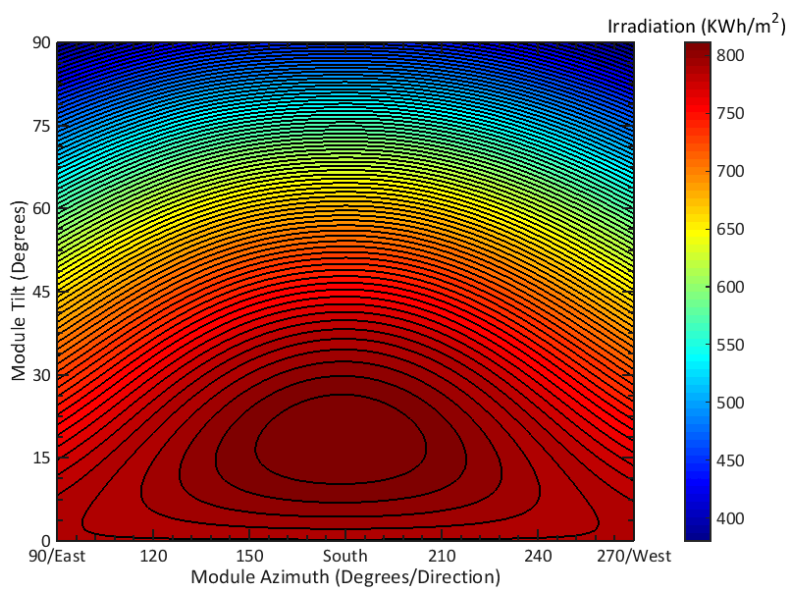

Fig. 4 PV module tilt and azimuth optimization with the Shading Factor applied.

Four different types of PV systems were studied. One is the autonomous system which is an off-grid system in which it relies solely on the output of the PV modules for its energy requirement. The second system is a conventional grid connected system in which the system can obtain/feed energy from/to the grid depending on the amount of available solar energy. Such systems generally do not need a battery to store energy as the grid is always available to step in if there is less solar energy available during the day or at night. Another type of system that is considered here is the hybrid system in which the system is a combination of off-grid and on-grid systems. The system has a battery and it is also connected to the grid. Such systems provide voltage stability and are advantageous when the load is predominantly DC. Finally the fourth kind is the autonomous hybrid system, which is similar to the hybrid system but differs due to its unidirectional interaction with the grid. The system is sized like an autonomous system and the 


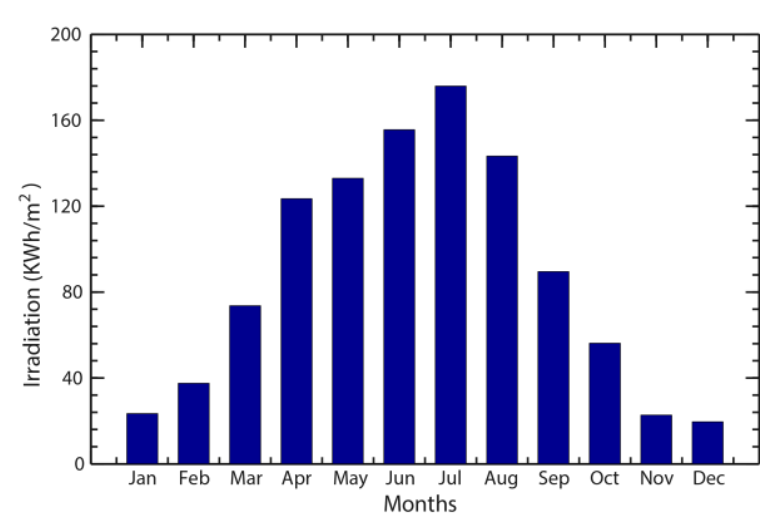

Fig. 5 Optimal inverter sizing ratio for different orientations and tilt angles grid connection is only to feed the excess energy in Summer to the grid as this would be wasted otherwise in an autonomous system.

The four systems were analysed under a load profile and the performance indicators such as the Loss of Load Probability (LoLP) and Energy Autarky were estimated. The LoLP is estimated as the ratio of total energy not met to the total energy demand from the load. It is the probability that the load is not delivered in an autonomous system and a low value therefore indicates a higher autonomy. Energy autarky is the ratio of self-generated energy consumed to

the total energy consumed and is an indicator of self-sustenance in grid assisted systems. In the Netherlands, the available energy peaks during Summer and drops drastically during Winter as shown in Fig. 5. This can be attributed to the longer days in Summer and shorter days in Winter. In such a scenario, further de-rated by the presence of shading elements in the surrounding of the chosen location, the autonomous systems require huge battery capacity and higher number of modules to maintain the load requirement even during the months of Winter. Therefore grid connected or hybrid systems may be more viable in such locations. A future contribution will report on the final design of our PV powered e-bike charging station.

\section{$\underline{P V \text { inverter sizing }}$}

PV arrays barely ever reach their installed peak power and the inverters that are connected to them are normally chosen per rated power (i.e. sized) to fit this installed rated power [5]. This method is far from optimal because it ignores that the behaviour of the solar panels is highly dependent on external factors such as the solar irradiance, the ambient temperature and the location of the installation. These parameters directly influence how much solar energy will hit the array on a daily basis and thus how much power will be delivered by the PV modules. Since the efficiency of an inverter is strongly linked to such input power, the size of the inverter is chosen accordingly. Considering all power levels that would be seen throughout a year at the input port of the inverter, designers can observe for how long a given inverter will work at lower or higher efficiency levels with respect to the nominal. The objective of this modelling is to find that inverter size for any given solar array when the installation characteristics are known. In this way the optimum inverter size guaranteeing the maximum annual energy yield can be indicated.

Focusing only on the AC power output coming from the inverter $\left(\mathrm{P}_{\mathrm{AC}}\right)$, by means of a mathematical function it is possible to recreate the efficiency curve of a given inverter if the manufacturer provides the curve on the datasheet or if the efficiencies at certain points along the curve are available. The inverter efficiency curve not only depends on the power but it also depends on the PV voltage it is working with. In this analysis, the effect of the voltage is not taken into consideration. Once the efficiency of the inverter as a function of the percentage of its nominal AC power is estimated, the efficiency curve is then translated from AC power into DC power as shown in Fig. 6. 


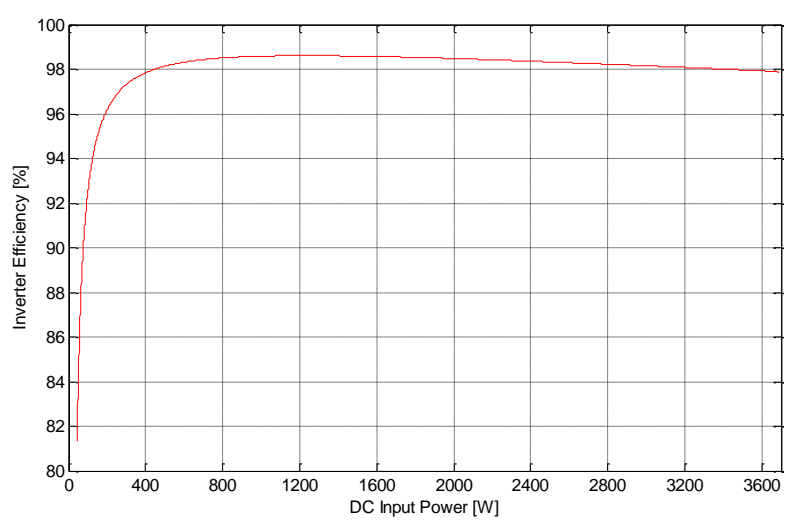

Fig. 6 Inverter efficiency vs DC input power

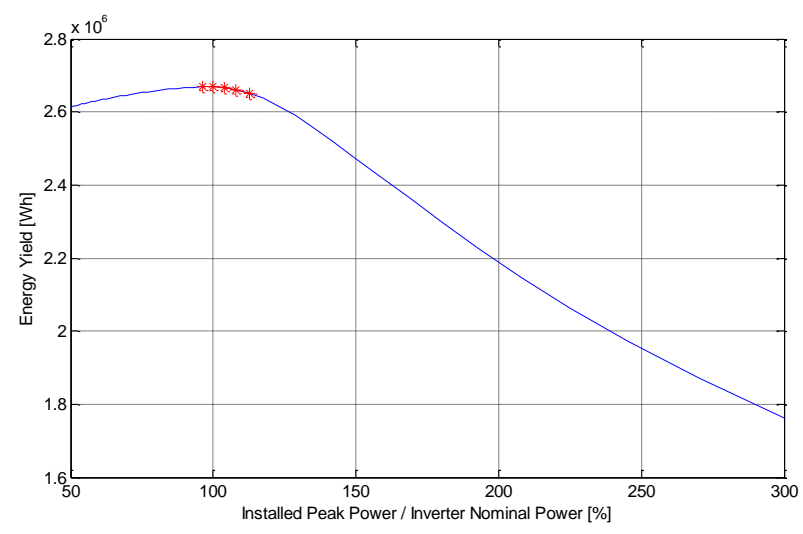

Fig. 7 Inverter dimensioning range for PV system installed in Spijkenisse, the Netherlands.

To start working on the dimensioning of the inverter, the definition for the concept of the "size" of an inverter according to what is used in the industry should be given. The inverter sizing is always relative to the installed peak power $\left(\mathrm{P}_{\text {peak }}\right)$ of the $\mathrm{PV}$ array it will be connected to. It can be expressed as a ratio of the installed peak power of the PV array to the nominal power of the inverter [6] [7] and can expressed as $R_{s}$. $R_{s}$ values were plotted against energy yield for a $2.7 \mathrm{~kW}_{\text {peak }}$ system in Spijkenisse, the Netherlands, whose measured data were also available and used to verify our model. It can be noticed from Fig. 7 that the maximum energy yield possible is not achieved by having an inverter the same size as the installed peak power of the solar array. It shows that over-dimensioning the inverter for this specific array will allow the user to retrieve more energy every year. The actual maximum energy yield that the model reports possible is $2.67 \mathrm{MWh}$ per year by using an inverter sizing of $96 \%$ approximately, which translates in an inverter size of $2.8 \mathrm{~kW}$ for the array of $2.7 \mathrm{~kW}_{\text {peak. }}$. It should be mentioned that the exercise performed to find the sizing range for the installation of the PV array located in Spijkenisse is only an example. Actually, the sizing range will vary depending on the location, orientation and inclination of the solar panels. On the northern hemisphere, for systems facing south with an optimal inclination angle, the inverter sizing is $<100 \%$. When rotating the system northwards, the sizing becomes larger and larger in percentage.

The process of properly sizing an inverter for a PV system considers the incoming DC power from the array and the variations in efficiency depending on the output power. If the inverter is oversized, the range of operation falls around the maximum point on the inverter efficiency curve. On the other hand, if the inverter is undersized, energy losses increase because when the input power is higher than the nominal power, the inverter cannot deliver more than its rated power value. In addition, when the array is installed far from the optimal site conditions, the expected DC power is lower. Therefore, under sizing the inverter might be a good solution to maximize the energy yield.

Fig. 8 and Fig. 9 show a distribution of the received power for a module tilted at $45^{\circ}$ and oriented South and North, respectively. The left vertical axis represents the amount of hours that a certain DC power level $\left(\mathrm{P}_{\mathrm{DC}}\right)$ is present over the total amount of time (in hours as well). When the solar array does not receive solar power, such time is not counted. Hence, night time is not included in our calculations. The width of the blue bars represent a certain power level and the height of each bar shows the amount of time that this power level is read at the terminals of the array. By multiplying every specific power level with the amount time this value is produced by 


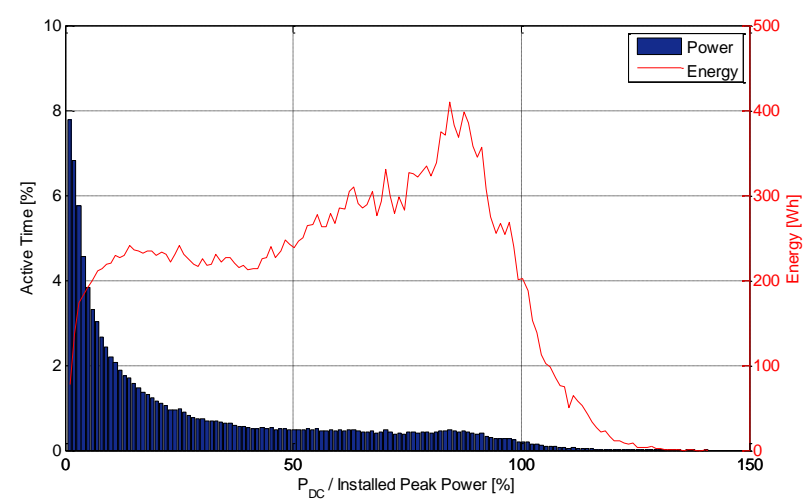

Fig. 8 DC power and energy distribution (Module facing south and tilted at $45^{\circ}$ )

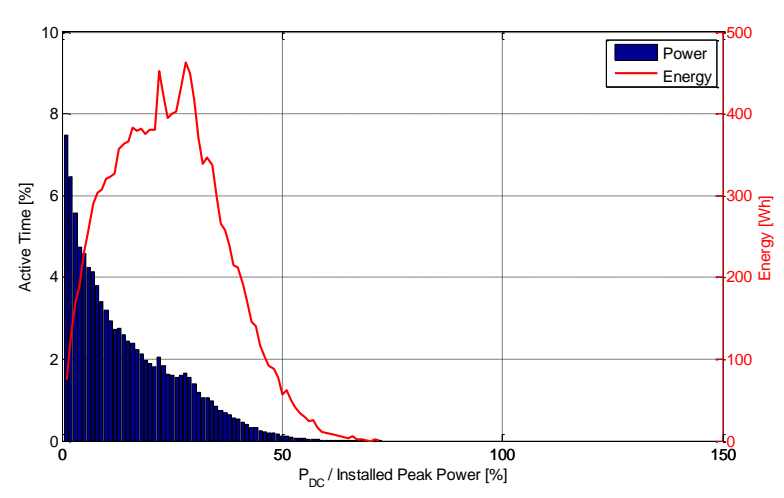

Fig. 9 DC power and energy distribution ( Module facing north and tilted at $45^{\circ}$ )

the solar array, the energy (E) being retrieved from that specific output can be calculated and plotted. The resulting energy that each power bar will translate into is presented as the red line.

It can be observed from Fig. 8 that the power that the array can deliver is not limited to $100 \%$ of the installed peak power. There are times over the entire year that the solar irradiance combined with the ambient temperature allows the output to be more than what was specified under STC. If the inverter size is chosen to match the $100 \%$ of the installed peak power, all the energy that could be harvested from these power levels will be lost due to the device operation restrictions. Similarly in Fig. 9, the inverter would hardly ever work at its maximum efficiency levels. Both cases illustrate that by choosing inverters that fit the environmental conditions at which the PV modules would be working at and the energy that the system will be handling at every stage, a better performing PV system can be obtained. To take into account the effect of module orientation and azimuth, a diagram similar to the one reported in Fig. 3 can be made to

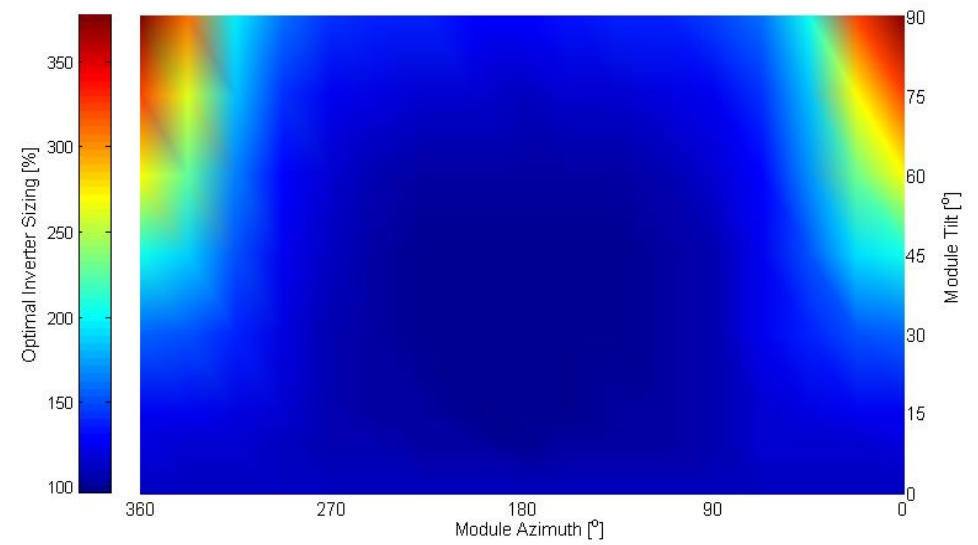

Fig. 10 Optimal inverter sizing ratio for different orientations and tilt angles quickly identify the inverter sizing for a particular installation (see Fig 10). In short, it is important to consider the actual output from the PV system when sizing the inverter as this can have a huge impact. A PV array with non-optimal orientation would produce lesser than rated and hence an under-sized inverter might be efficient and cost-effective.

\section{CONCLUSIONS}

With the Dutch PV portal, a realistic modelling tool to simulate performances of PV systems in Netherlands based on real time meteorological data was achieved. By using the complex fluid dynamic model and actual inverter efficiencies, the modelling provides a very accurate yield prediction. From a societal perspective the portal aimed at creating an interactive tool where a vast audience could gain a greater insight on the PV potential in the country. 
In this contribution we also discussed about deriving a shading factor using the Horicatcher to take into account the effect of shading from surroundings on the energy yield from a PV system. The resultant yield was then used to identify the optimum orientation for the PV modules that provides the maximum yield. This optimization can also be used to identify the ideal orientation based on the system design and purpose (autonomous, hybrid etc.).

The inverter sizing model will help in the accurate energy yield predictions on the AC side. It was shown that the model can estimate the inverter size that provides the highest annual energy yield by running the inverter at its most efficient operating range. By estimating the orientation dependence of the inverter sizing, installers can easily size the inverters for roofs of any orientation and tilt. All the models can be applied globally as long as the local weather data is available for a fair and accurate prediction.

\section{REFERENCES}

1. Koninklijk Nederlands Meteorologisch Instituut (http://www.knmi.nl/index_en.html (accessed March 2015)

2. M. K. Fuentes, A Simplified Thermal Model for Flat-Plate Photovoltaic Arrays, Sandia National Laboratories report (1987) (http://prod.sandia.gov/techlib/accesscontrol.cgi/1985/850330.pdf, accessed March 2015).

3. Sandia national laboratories inverter database, Sandia National Laboratories (2014) (https://sam.nrel.gov/content/component-databases, accessed March 2015).

4. http://www.meteotest.ch/en/footernavi/solar_energy/horicatcher/ (accessed March 2015)

5. B. Burger and R. Rüther, Inverter sizing of grid-connected photovoltaic systems in the light of local solar resource distribution characteristics and temperature, Solar Energy 80, 32-45 (2006).

6. Steca Elektronik (http://www.steca.com/index.php?StecaGrid_Portal_registration, accessed March 2015).

7. The German Energy Society (Deutsche Gesellshaft für Sonnenenergie), Planning \& Installing Photovoltaic Systems, A guide for installers, architects and engineers, Earthscan (2008). 